\title{
Recurrent Dermatofibrosarcoma Protuberans with Pigmentation and Myoid Differentiation
}

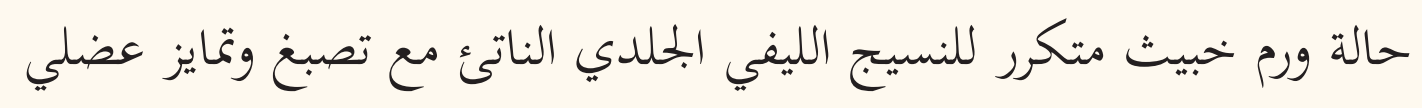

سوريكا ياداث، نيدي ثيرما، نيتا كورانا، سوشانت نيوجي

ABSTRACT: Dermatofibrosarcomas protuberans (DFSP) are rare low-grade tumours with various subtypes and usually occur among middle-aged adults. However, myoid differentiation is very rare. We report a 44-year-old woman who presented to the Lok Nayak Jai Prakash Hospital, New Delhi, India, in 2017 with a recurrent pigmented DFSP presenting as an arm swelling. Upon histological and immunohistochemical analysis, myoid differentiation was confirmed. A literature review of the clinical and histopathological features of this rare entity is presented.

Keywords: Dermatofibrosarcoma Protuberans; Melanocytes; Pigmentation; Cell Differentiation; Case Report; India.

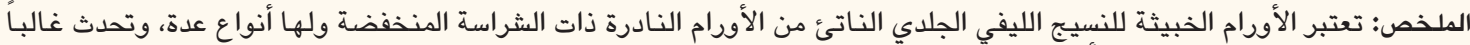

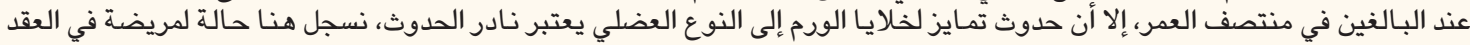

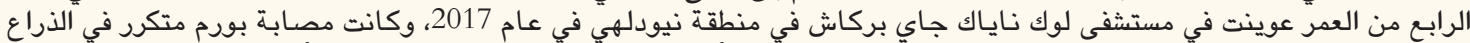

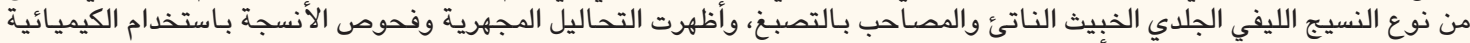

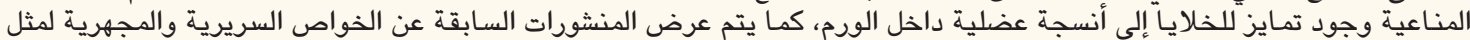
هذه الحالة النادرة الحدوث. الكلمات المفتاحية: ورم النسيج الليفي الجلدي الخبيث الناتئ؛ الخلايا الصبغية؛ التصبخ، تمايز الخلايا؛ تقرير حالة؛ الهند.

$\mathrm{D}$ ERMATOFIBROSARCOMAS PROTUBERANS (DFSP) are rare low-grade sarcomas involving the dermis and subcutaneous tissue. ${ }^{1,2}$ This type of tumour has a low rate of distant metastasis, but a higher rate of local recurrence. Histological subtypes of DFSP include giant-cell, pigmented, sclerosing, atrophic, myoid and fibrosarcomatous types. ${ }^{1,2}$ Of these, pigmented DFSP are characterised by interspersed melanin-rich dendritic cells and are very rare, accounting for less than $5 \%$ of all reported cases of DFSP. ${ }^{1}$ However, the origin of myoid differentiation in DFSP and its clinical significance is unknown. This case report describes a case of myoid differentiation in recurrent pigmented DFSP presenting as an arm swelling in an adult female patient.

\section{Case Report}

A 44-year-old woman presented to the Lok Nayak Jai Prakash Hospital, New Delhi, India, in 2017 with a recurrent mass on her right upper arm. The tumour had regrown since being surgically removed three years prior, at which time it had been histopathologically diagnosed as a DFSP. At presentation, the lesion was attached to the overlying skin, measuring $8 \times 7 \times 6 \mathrm{~cm}$.
A computed tomography (CT) scan showed a homogeneously-enhancing soft tissue lesion in the subcutaneous plane of the lateral aspect of the middle-third of the right arm, measuring $7 \times 6 \times 4.5 \mathrm{~cm}$ [Figure 1A]. The lesion had well-defined margins except medially, where it was abutting the deltoid muscle with the loss of the intervening fat planes. However, CT scans of the chest, abdomen and head and neck region were normal. There was no evidence of organomegaly or lymphadenopathy. The patient subsequently underwent wide surgical excision of the lesion.

Upon gross examination, the excised soft tissue mass measured $13 \times 11 \times 5 \mathrm{~cm}$. The surface of the lesion showed a firm homogenous polypoidal greyish-white growth of $6 \times 6 \times 4.5 \mathrm{~cm}$, which extended deep into the underlying dermis [Figure 1B]. There were no areas of haemorrhage or necrosis. Histologically, the overlying skin was unremarkable. The tumour itself was located in the dermis and was composed of monomorphic spindle cells arranged in a storiform and fascicular pattern with a parallel arrangement of cells [Figure 2A]. In certain areas, the tumour was more cellular and composed of elongated cells with moderate cytoplasm and elongated-to-plump nuclei, which were mostly perivascular [Figure 2B]. The eosinophilic cells were 


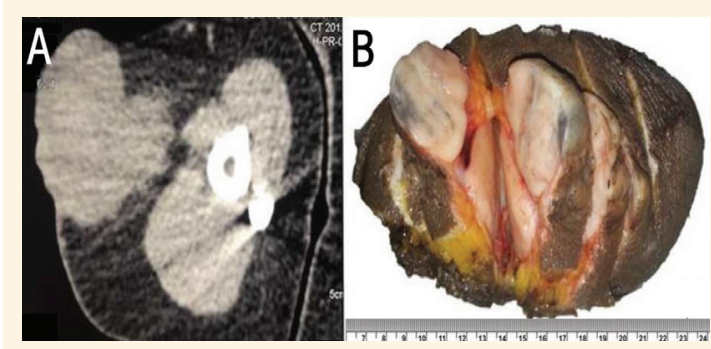

Figure 1: A: Contrast-enhanced computed tomography of a recurrent swelling in the right arm of a 44-year-old woman showing a homogenously-enhancing mass. B: Gross photograph of the excised lesion showing a greyish-white mass with stretching of the overlying skin.
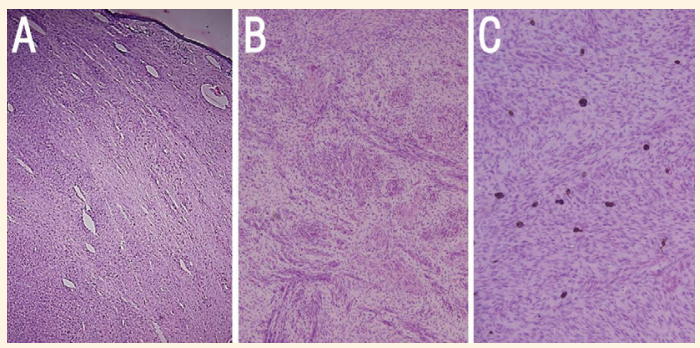

Figure 2: Haematoxylin and eosin stains at (A) x100 magnification and (B) x200 magnification showing areas of myoid differentiation and $(\mathbf{C})$ at $\times 400$ magnification showing monomorphic spindle cells with interspersed pigmented cells.

bland-looking without pleomorphism or mitotic figures. The focal tumour cells contained brown intracellular pigment [Figure $2 \mathrm{C}$ ]. The tumour had infiltrated the underlying soft tissue; however, all of the resected margins, including the circumferential resected margins and deep resection plane, were tumour-free. There was no evidence of mitosis, cellular atypia or necrosis.

An immunohistochemical panel of the tumour cells showed diffuse expression of vimentin and cluster of differentiation (CD)34 [Figure 3A]. The cells with eosinophilic cytoplasm showed immunohistochemical expression of smooth muscle actin, indicative of myoid differentiation [Figure 3B]. These areas were negative for CD34 [Figure 3C]. The final diagnosis was of a recurrent DFSP with pigmentation and myoid differentiation. At a six-month follow-up appointment, the patient was symptom-free and there was no sign of disease recurrence.

\section{Discussion}

In general, DFSP occur mostly in middle-aged adults, but have been reported in patients between $8-87$ years old. ${ }^{3}$ Men are affected more often than women at a ratio of 2.3:1. ${ }^{4}$ This type of tumour is usually painless and presents as a long-standing solitary multinodular mass. Commonly affected sites include the trunk, particularly the back, and the limbs, chest and head and neck region. ${ }^{1,3}$ The tumour is locally aggressive and usually infiltrates the deep dermis and subcutaneous fat. ${ }^{3}$ A genetic study found that $89 \%$ of DFSP cases had collagen type I alpha 1 platelet-derived growth factor $\beta$ fusion transcripts. ${ }^{4}$ A classical histological feature of DFSP is a storiform growth pattern of benign-looking spindle cells. Histopathologically, CD34 is considered a highly-specific marker of DFSP. ${ }^{5}$

The origin of muscle differentiation in DFSP is debatable. Calonje et al. first described myoid differentiation in five cases of DFSP either with or without fibrosarcomatous components; because the myoid areas were distributed throughout the tumour, the authors concluded that these cells form their own areas. ${ }^{6}$ O'Connell et al. studied two cases of fibrosarcoma arising in DFSP and came to a similar conclusion. ${ }^{7}$ Other researchers have claimed that myoid differentiation is solely a reactive phenomenon, with stromal myofibroblasts showing some degree of hyperplasia., ${ }^{8,9}$ SanzTrelles et al. concluded the myoid areas in DFSP to be the result of vascular smooth muscle cell hyperplasia or the proliferation of pericytes. ${ }^{10}$ Another study demonstrated a close relationship between blood vessels in the tumour and areas of myoid differentiation. ${ }^{11}$ Ohtani et al. found smooth muscle actinexpressing myoid cells in a case of fibrosarcomatous DFSP which had metastasised to the lung; the researchers suggested that myoid differentiation may therefore be neoplastic in origin. ${ }^{12}$ However, no relationship between the myoid areas and the blood vessels was found; furthermore, these areas differed in appearance from the pericytes. ${ }^{12}$
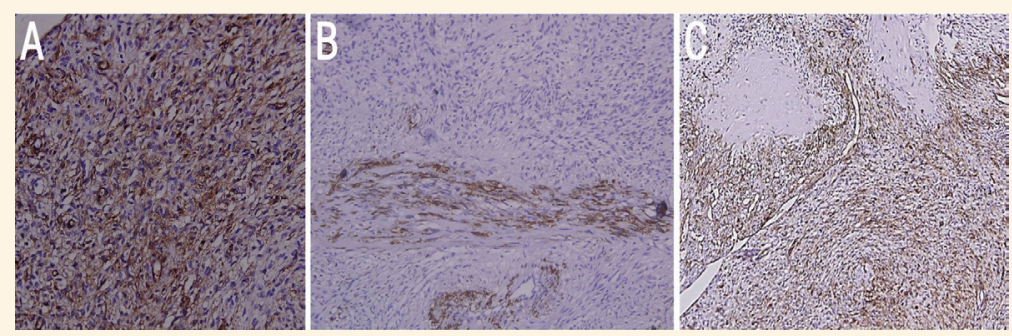

Figure 3: Immunohistochemical panel at x200 magnification showing (A) diffuse positivity for cluster of differentiation (CD)34 and (B) smooth muscle actin expression in areas of myoid differentiation and (C) negativity for CD34. 
The pigmented subtype of DFSP, also known as a Bednar tumour or storiform neurofibroma, contains varying amounts of melanotic pigment. ${ }^{13}$ This subtype is different from conventional DFSP and has specific chromosomal abnormalities. ${ }^{14}$ However, the origin of pigmented DFSP is still unknown. Some researchers advocate a neuroectodermal origin due to the presence of cells of Schwannian differentiation along with dendritic melanocytes, while others believe that such tumours arise after trauma, scarring from vaccinations or insect and animal bites. ${ }^{15,16}$ Although several cases of DFSP with fibrosarcomatous differentiation are available in the literature, the current case appears to be the first report of recurrent DFSP with myoid differentiation and pigmentation. ${ }^{17-19}$

\section{Conclusion}

Myoid differentiation is a morphological variant of DFSP. In the current case, myoid differentiation was found around the blood vessels in the tumour, distributed irregularly without forming a specific stromal pattern. It is possible that hyperplastic myofibroblasts occur due to a reactive process to proliferating tumour cells. However, further studies are needed to enhance our understanding of myoid differentiation and its clinical prognosis in DFSP cases.

\section{References}

1. Zhang J, Zhang RS, Wei X, Shi QL, Zhou XJ, Ma J. [Pigmented dermatofibrosarcoma protuberance: A clinicopathologic analysis of 7 cases]. Zhonghua Bing Li Xue Za Zhi 2013; 42:810-14. doi: 10.3760/cma.j.issn.0529-5807.2013.12.005

2. Laskin WB. Dermatofibrosarcoma protuberans. CA Cancer J Clin 1992; 42:116-25. doi: 10.3322/canjclin.42.2.116.

3. Mentzel T, Beham A, Katenkamp D, Dei Tos AP, Fletcher CD. Fibrosarcomatous ("high-grade") dermatofibrosarcoma protuberans: Clinicopathologic and immunohistochemical study of a series of 41 cases with emphasis on prognostic significance. Am J Surg Pathol 1998; 22:576-87. doi: 10.1097/00000478-199 805000-00009.

4. Llombart B, Sanmartin O, Lopez-Guerrero JA, Monteaqudo C, Serra C, Requena C, et al. Dermatofibrosarcoma protuberans: Clinical, pathological, and genetic (COL1A1-PDGFB) study with therapeutic implications. Histopathology 2009; 54:860-72. doi: 10.1111/j.1365-2559.2009.03310.x.

5. Goldblum JR, Tuthill RJ. CD34 and factor-XIIIa immunoreactivity in dermatofibrosarcoma protuberans and dermatofibroma. Am J Dermatopathol 1997; 19:147-53. doi: 10.1097/ 00000372-199704000-00008.
6. Calonje E, Fletcher CD. Myoid differentiation in dermatofibrosarcoma protuberans and its fibrosarcomatous variant: Clinicopathologic analysis of 5 cases. J Cutan Pathol 1996; 23:30-6. doi: 10.1111/j.1600-0560.1996.tb00774.x.

7. O'Connell IX, Trotter MI. Fibrosarcomatous dermatofibrosarcoma protuberans with myofibroblastic differentiaion: A histologically distinctive variant. Mod Pathol 1996; 9:273-8.

8. Morimitsu Y, Hisaoka M, Okamoto S, Hashimoto H, Ushijima M. Dermatofibrosarcoma protuberans and its fibrosarcomatous variant with areas of myoid differentiation: A report of three cases. Histopathology 1998; 32:547-51. doi: 10.1046/j.1365-2559.1998. 00428.x.

9. Sanz-Trelles A. Myoid cells in the fibrosarcomatous variant of dermatofibrosarcoma protuberans. Are they neoplastic? Histopathology 1999; 34:179-80.

10. Sanz-Trelles A, Ayala-Carbonero A, Rodrigo-Fernández I, Weil-Lara B. Leiomyomatous nodules and bundles of vascular origin in the fibrosarcomatous variant of dermatofibrosarcoma protuberans. J Cutan Pathol 1998; 25:44-9. doi: 10.1111/j.16000560.1998.tb01688.x.

11. Diaz-Cascajo C. Myoid differentiation in dermatofibrosarcoma protuberans and its fibrosarcomatous variant. J Cutan Pathol 1997; 24:197-8. doi: 10.1111/j.1600-0560.1997.tb01577.x.

12. Ohtani N, Fukusato T, Tezuka F. Sarcomatous dermatofibrosarcoma protuberans metastasized to the lung: Preservation of CD34 expression in tumor cells. Pathol Int 1998; 48:989-93. doi: 10.1111/j.1440-1827.1998.tb03872.x.

13. Bednar B. Storiform neurofibromas of the skin, pigmented and nonpigmented. Cancer 1957; 10:368-76. doi: 10.1002/1097-0142 (195703/04)10:2<368::AID-CNCR2820100218>3.0.CO;2-3.

14. Sirvent N, Maire G, Pedeutour F. Genetics of dermatofibrosarcoma protuberans family of tumors: From ring chromosomes to tyrosine kinase inhibitor treatment. Genes Chromosomes Cancer 2003; 37:1-19. doi: 10.1002/gcc.10202.

15. Elder DE, Massi D, Scolyer RA, Wilemze R, Eds. Dermatofibrosarcoma protuberans and variants. In: World Health Organization Classification of Skin Tumours, 4th ed. Lyon, France: IARC Press, 2018. Pp. 304-6.

16. Llombart B, Serra-Guillén C, Monteagudo C, López Guerrero JA, Sanmartín O. Dermatofibrosarcoma protuberans: A comprehensive review and update on diagnosis and management. Semin Diagn Pathol 2013; 30:13-28. doi: 10.1053/j.semdp.20 12.01.002.

17. Porter C, Vincetic A, Saleh ME, Goldstein H. Pigmented dermatofibrosarcoma protuberans of the foot with fibrosarcomatous changes: A review and case presentation. J Foot Ankle Surg 2002; 41:186-91. doi: 10.1016/S1067-2516(02)80070-9.

18. Suehara Y, Yazawa Y, Hitachi K. Metastatic Bednar tumor (pigmented dermatofibrosarcoma protuberans) with fibrosarcomatous change: A case report. J Orthop Sci 2004; 9:662-5. doi: 10.1007/s00776-004-0831-2.

19. Kini H, Raghuveer CV, Pai MR, SK. Fibrosarcomatous Bednar tumor with distant metastases: A case report. Indian J Pathol Microbiol 2004; 47:26-9. 